\title{
Advertisement Spending and Income: An Aggregative Analysis
}

\author{
Baiding Hu*, Amal Sanyal \\ Faculty of Agribusiness and Commerce, Lincoln University, Christchurch, New Zealand \\ Email: "Baiding.Hu@lincoln.ac.nz
}

Received 15 March 2016; accepted 26 April 2016; published 29 April 2016

Copyright $@ 2016$ by authors and Scientific Research Publishing Inc.

This work is licensed under the Creative Commons Attribution International License (CC BY).

http://creativecommons.org/licenses/by/4.0/

(c) (i) Open Access

\begin{abstract}
Existing studies tend to investigate cross-sectional relations between GDP and advertisement at the firm or industry level. The present study focuses on the long-run relation between GDP and aggregate advertisement spending using United States data for the period 1900-2007. Granger causality tests indicate the temporal precedence of GDP. A cointegration analysis shows that, as GDP increases, it causes advertisement spending to increase at a rate faster than its own growth. Faster growth relative to GDP is accompanied with a negative autonomous trend of advertisement spending. This trend appears consistent with the continuous technical progress in advertisement.
\end{abstract}

\section{Keywords}

Advertisement Spending, GDP, Granger Causality, Cointegration

\section{Introduction}

This paper explores the long-run behaviour of aggregate advertisement spending. It explores two questions specifically. The first is if there is a statistically robust long-run relation between GDP and aggregate advertisement spending. At the firm and industry levels, econometric studies have estimated multiple regression models of ad spending with variables like sales, profit, market concentration, price elasticity of demand and other relevant variables. But firm level effects can produce ambivalent longer-run consequences for the firm itself and the industry to which it belongs; and the effects may or may not be similar to the single period relations ${ }^{1}$. For example, while ad spending and sales are positively correlated in a cross-section, scale economy from successful ads can reduce the amount of spending per unit of output over time. On the other hand, by increasing sales at the firm

\footnotetext{
"Corresponding author.

${ }^{1}$ Conflicting effects of advertising on price and output was discussed quite early, e.g. [1], who maintained that the net effect depends on "the facts of the case", [1], p. 167.
} 
level, ad spending can increase industry concentration, and eventually restrict output. In that case ad spending would increase as a proportion of industry output. Hence cross-section studies do not lead to any unambiguous expectation about the aggregate relation between GDP and ad spending.

The second aim is to explore the time trend of aggregate ad spending independently of its relation with GDP. Is ad spending expected to increase, fall or stay unchanged in a hypothetical state where GDP is stationary? This question is worth asking as the medium of advertisement has evolved through prints, billboards, radio, television, phones, internet and electronic social media producing a time-varying mix of media over the horizon of analysis. Each medium has a characteristic aggregate fixed resource cost for the economy independent of the amount of output advertised or its effect on GDP. At the same time, the mix of search and experience goods, with (presumed) difference of advertising intensity, has changed significantly. Given the multitude of influences, how aggregate cost of advertising has evolved, independently of its relation with GDP, is an important question. Micro-level studies do not throw any light on this question either.

To proceed with these questions we explore if there are statistically significant long run relations between GDP and aggregate ad spending, and any significant temporal trend independent of GDP. Generally cross-section studies focus on both sales and profits as variables of interest. But we will focus on GDP alone, because the method of accounting for intangible capital formed with advertising (goodwill and brands) would influence profit estimates for our study significantly. Though certain theoretical ideas are available for this issue, it is difficult to match them with data without making large compromises.

We analyze the time series of GDP and total advertisement expenditure in the US over 1900 to 2007. For ad spending the data set is "Historical U.S. advertising expenditure data" from purplemotes.net, first posted in September 2008 and the source of GDP data is www.measuringworth.com. US advertisement industry was already well developed by $1900^{2}$. So the time series used in this paper avoids possible teething problems of the development of an advertisement culture as well as that of an infant ad industry. We therefore expect to get a long-run view of the aggregate relations in an already established advertising culture and industry.

Firm level studies where ad spending is used as an independent variable influencing sales and profits have to reckon with the problem that ad spending may in fact be an endogenous variable ${ }^{3}$. This has led to fine-tuning of econometric procedures as also problems of interpretation. The question of endogeneity is important at macroeconomic level too. Quite apart from the endogenous nature of firm-level ad spending, there are a number of macro channels that tie up ad spending and GDP in two-way relations. These are the effects of spillover outside the industry where ad spending occurs, and include income multiplier effects on aggregate demand, supply side effects from inputs needed for the ad industry and so on. Studies quantifying these influences report significant effect of advertisement on GDP through these channels ${ }^{4}$. In view of a two-way relation between ad spending and GDP it will be useful to analyze Granger causality properties of the data set as well.

The paper is organized as follows. In the next section we discuss the reasons why cross-sectional literature is inconclusive about aggregate questions. In Section 3 we present a time series analysis of aggregate ad spending and GDP in the US. This section presents three exercises. First, we analyze if there have been structural breaks in our data set. Given the long horizon of analysis, structural breaks are probable and, if not accounted for, would distort the long run statistical relations. Secondly, we estimate a cointegrating relation which throws light on the long run co-behavior of ad spending and GDP as also the temporal behavior of ad spending. The third exercise is Granger causality analysis. In Section 4, we discuss the implications of cointegration and Granger causality results and place them in the context of the discussion of Section 2. Section 5 concludes the paper.

\section{Cross-Section Studies and the Project of Aggregation}

As discussed in the introduction, the aim of this paper is to explore the existence of any simple and robust aggregate relation. If $x$ and $y$ denote aggregate ad spending and GDP, both in nominal terms, and $T$, a time index, then we are seeking if a stable relation $x=f(y, T)$ exists. Empirical work on advertisements, starting in the late 1950 's, has continuously refined its methods to tackle a variety of methodological and data problems and has

${ }^{2}$ For a statistical overview of the state of US advertisement around 1900, see [2]. A timeline of important developments between 1850 and 1920 is available at http://library.duke.edu/digitalcollections/eaa/timeline/, provided by Duke University Library. For an evolutionary account see [3] and [4].

${ }^{3}$ Endogeneity was discussed as a problem for the empirical literature quite early. A thorough discussion is available in [5] Schmalensee (1972).

${ }^{4}$ For example, [6] for UK; [7] for the US economy. 
produced a rich literature ${ }^{5}$. By and large it reports that firms that spend more on ads also sell more, and industries with higher ad spending are also more profitable. This does not, however, imply a similar positive relation between GDP and ad spending either at a point of time or through time. Ad spending is expected to boost current sales leading to the observed positive correlation. But follow-up spending on advertisement is based on the current period's effects of spending on demand and cost of the firm. These effects are often contradictory as we discuss below and they make the ratio of ad spending to sales unpredictable $a$ priori.

Advertising increases firms' unit cost of production-cum-sale. In relatively homogeneous products with zeroprofit long run equilibrium, this should lead to price increases. Given the industry demand curve, industry output would fall resulting in an increase of the ratio of ad spending to output. The ratio of ad spending to the nominal value of industry output would then depend on the price elasticity of demand and can rise as well as fall 6 . On the other hand, if advertisement shifts the industry demand curve upward, say because of information and persuasion, then the effects of unit cost increase may be partly or wholly neutralised. Thus the net result cannot be anticipated in either case. Nor is it expected to be either positive or negative for all markets.

Markets with monopolistic competition are also subject to ambivalent effects ${ }^{7}$. Suppose first that a firm's ad has effect only on its own demand curve and the industry demand curve is not affected. As suggested by empirical studies, assume that firms with higher ad spending have a larger part of industry demand. This would make their individual demand curves less price-elastic and would lead to price increase after a lag. As these firms restrict output, industry output will also fall, ceteris paribus. It implies an increase in the ratio of ad spending to quantity of output over time. Its ratio to the nominal value of industry output would depend on the price elasticity of demand and cost functions of those firm(s) that grew in relative market share.

On the cost side, increasing return to scale for the product and diminishing returns to advertisement introduce more ambiguity. Firms that succeed to increase sales significantly often realise economy of scale in production. This is particularly true of oligopoly where individual firms have large market shares. Often such firms pass a part of the cost saving to the product price in order to increase market share further. This changes the ratio of ad spending per unit sale. But the direction and amount cannot be predicted as they would depend on price elasticity of demand.

Diminishing returns to advertising in terms of effect on sales introduces a tendency for ad costs to increase in relation to revenue. Further, as [12] observed, the effect is accentuated at the industry level because late-entrants to an industry can compete only with progressively more costly campaigns. The tendency of increasing ad costs is expected to be particularly high for experience goods. It has been argued (e.g. [13]) that for experience goods ad campaigns work as quality signals. They increase initial sales significantly because of the quality message. But long-term sales are driven more by firm-specific factors, e.g. the ability to sustain/improve quality and get repeat buyers and referrals, thus resulting in diminishing return to the original ads. As a result, ad cost per unit value of product has a tendency to increase significantly over time for experience goods ${ }^{8}$. On the other hand, firms financing bigger campaigns are also the more efficient ones. Simultaneously with advertisement, they try demand expansion through other means like quality improvement and better distribution and outreach. This may lead to a fall in the ratio of ad spending to sales. Therefore the behaviour of advertisement expenditure and GDP is not predictable on the basis of either microeconomic theory or cross-sectional empirical results.

The second question explored in our exercise is the path of aggregate ad spending through time. If the effect of economic growth is removed, the residual variation would be due to change in the cost of unit advertisement and its effectiveness. There is a large literature addressing the effectiveness of advertisement campaigns, innovations, and $\operatorname{costs}^{9}$. Though it provides significant insight on techniques and effects, it does not enable quantification of macro relations. A macro time series analysis is expected to help find if any systematic and robust relation at all exists among ad spending, GDP and time. This in short is the motivation of the time series study of the next section.

\footnotetext{
${ }^{5}$ Important early contributions are [8] and [9]. [10] provided an extensive survey of work up to the end of eighties; a more recent survey is available in [11].

${ }^{6}$ Because the focus of our paper is GDP, we are interested in the nominal value rather than quantity of output at firm and industry level. ${ }^{7}$ After [1] seminal work in this regard, there have been significant theoretical discussions supporting the view.

${ }^{8}[14]$ and [15] present a variety of empirical evidences in support of this hypothesis.

${ }^{9}$ Most of this literature has been published in journals like Journal of Advertising Research, International Journal of Advertising, Journal of Current Issues \& Research in Advertising, International Journal of Internet Marketing and Advertising, and in journals of marketing and consumer psychology. Some references for specific contexts appear below.
} 


\section{Aggregate Time Series Analysis}

This section reports on econometric analysis in search of a possible long-run equilibrium relation between GDP and aggregate advertisement spending (AS). US time series data used here spans the period 1900 to 2007 -a period that has seen a number of economic and financial upheavals. Therefore the possibility of structural breaks has been taken into account in unit-root testing and the subsequent cointegration analysis. A summary of the data is provided in Table 1 in terms of level i.e. $\ln G D P_{t}$ and $\ln A S_{t}$, and first differences $\Delta \ln G D P_{t}$ and $\Delta \ln A S_{t}$.

\subsection{Unit-Root Tests and Structural Breaks}

Since [16] there is a consensus that it is necessary to test macroeconomic time series variables for (non) stationarity before using them in analysis. While Augmented Dicky-Fuller (ADF) test originating from ([17]) is widely used, a number of other tests have been developed to supplement for its deficiencies and to broaden testable hypotheses on underlying data generating processes. Perron ([18]) showed that failure to allow for an existing break leads to a bias that reduces the power of the ADF and proposed allowing for a known or exogenous structural break in the test. Zivot and Andrews ([19]) however later argued that Perron's procedure implies testing unit root based on the outcome of a prior test for a structural break point, thus making it subject to issues associated with pre-testing. They then suggested a new test (ZA test) that lets the data determine the structural break points. Phillips and Perron ([20]) developed a test that does not require the selection of lag length which the ADF test does. Further, unlike the ADF procedure, the PP test is robust to heteroskedastic residuals in the test regression.

All of these tests are asymptotic and their finite sample properties are unknown. This led Elliott, Rothenberg and Stock ([21]) to propose a family of point optimal invariant tests that outperform ADF in terms of power in small samples when the series has unknown deterministic components. The test is named DF-GLS as data is transformed before running the Dicky-Fuller OLS regression to compute the test statistic. While these tests have been constructed under the null hypothesis that the series follows a unit-root process, the KPSS test, due to Kwiatkowski, Phillips, Schmidt and Shin ([22]), has been developed to test a stationary null. The motivation of the KPSS test stems from the fact that the ADF and PP tests have low power against alternative hypothesis suggesting more non-rejections of a unit root than there ought to be.

Given this backdrop, we subjected our data to all of the five tests to get a comprehensive idea of the data generation processes. Figure 1 and Figure 2 show that while $\ln G D P_{t}$ and $\ln A S_{t}$ exhibit nonstationarity, the first differences $\Delta \ln G D P_{t}$ and $\Delta \ln A S_{t}$ appear to be stationary, and hence the two variables are likely to be integrated of order one, denoted I (1). Table 2 summarises the unit root testing results on the natural logarithm of the variables. On the levels of the variables, only the ZA test rejects the unit root null in favor of trend stationarity. On the first differences, all the test statistics reject the unit root null, therefore there is strong evidence that the levels of the two variables are I (1).

ZA test indicates that the level variables have a structural break in 1930 and the first differences have one in 1934. This suggests that the Great Depression might have altered the data generating process and that it needs to be taken into account in further exercises and interpretation.

\subsection{Vecm Analysis}

Here we provide a Vector Error Correction Model (VECM) of the short-run and long-run relations between Ad Spending and GDP. Existence of a long-run relation is typically explored with a series of Johansen's [23] likelihood ratio (LR) tests for cointegration. Since the levels of the two variables are I (1), we explore if there is a cointegration relation between them.

Table 1. Descriptive statistics.

\begin{tabular}{cccccc}
\hline Variable & Obs & Mean & Std. Dev. & Min & 9.9411 \\
\hline $\ln G D P_{t}$ & 108 & 13.0237 & 2.0097 & 6.1092 & 16.4883 \\
$\ln A S_{t}$ & 108 & 9.1901 & 1.9427 & 0.0759 & 0.2630 \\
$\Delta \ln G D P_{t}$ & 107 & 0.0612 & 0.08964 & -0.2595 \\
$\Delta \ln A S_{t}$ & 107 & 0.0601 & 0.4424 \\
\hline
\end{tabular}




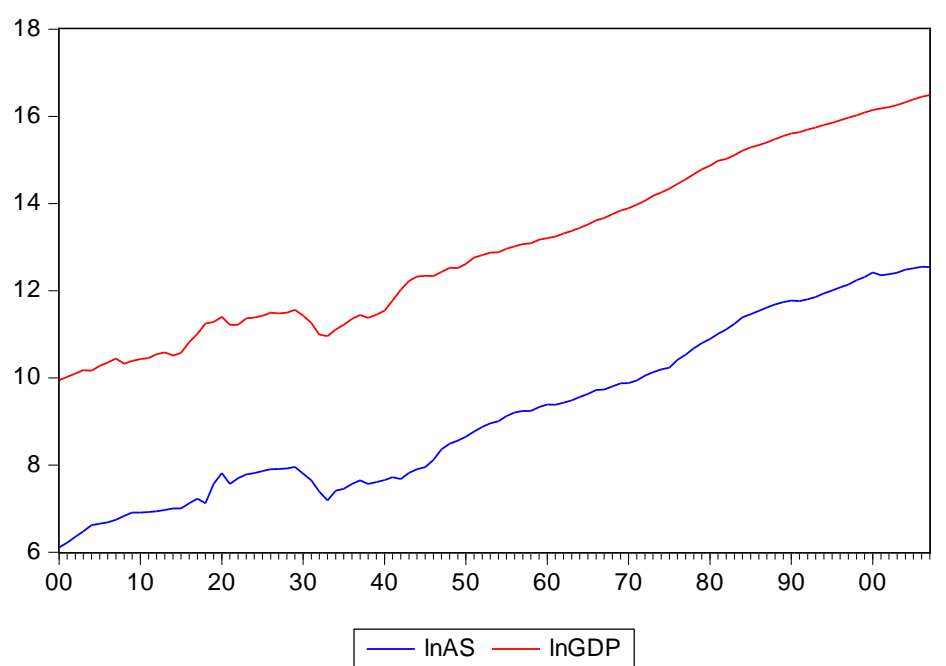

Figure 1. Logs of nominal advertisement spending and GDP: 1900-2007.

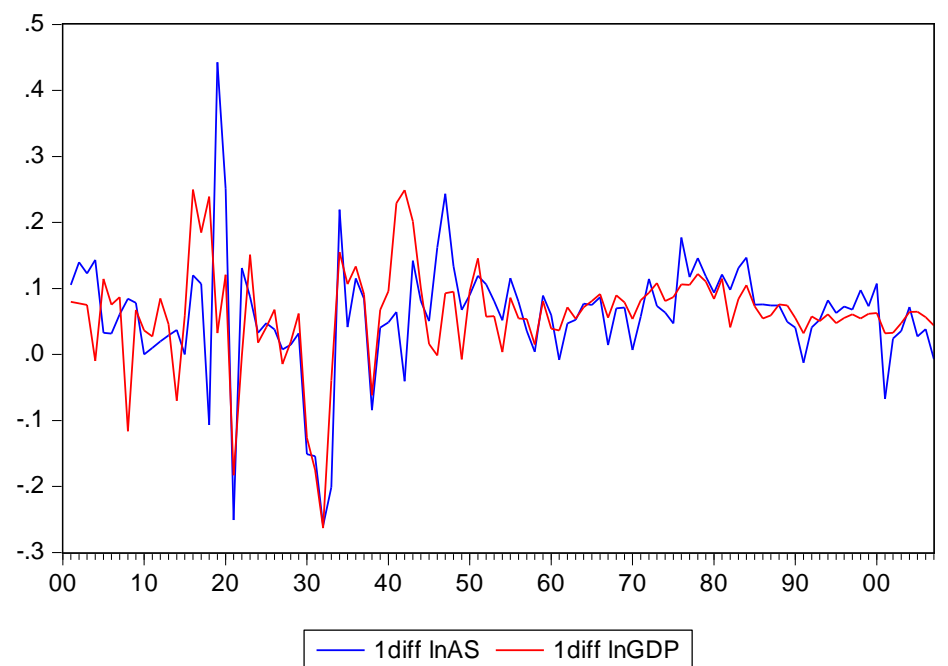

Figure 2. 1st differences of logs of nominal advertisement spending and GDP: 1900-2007.

Table 2. Unit-root tests.

\begin{tabular}{cccccc}
\hline & ADF & ZA & PP & DFGLS & KPSS \\
\hline $\ln G D P_{t}$ & -1.597 & $-5.424^{* *}$ & 0.365 & -1.215 & $0.360^{* * *}$ \\
$\ln A S_{t}$ & -1.255 & $-5.504^{* *}$ & 0.100 & -1.893 & $0.403^{* * *}$ \\
$\Delta \ln G D P_{t}$ & $-6.510^{* * *}$ & $-7.537^{* * *}$ & $-6.385^{* * *}$ & $-3.848^{* * *}$ & 0.058 \\
$\Delta \ln A S_{t}$ & $-8.270^{* * *}$ & $-5.341^{* *}$ & $-8.382^{* * *}$ & $-2.877^{* *}$ & 0.085 \\
\hline
\end{tabular}

${ }^{* * *}$ significant at $1 \% ;{ }^{* *}$ significant at $5 \%$.

As is well-known, the power of LR tests is sensitive to the VECM specification and particularly to the deterministic components of the model [24]. This calls for either identifying or ruling out any events that may intervene in the long-run and short-run relations between ad spending and GDP. As both time series processes showed structural shift in the early 1930s any long-run equilibrium relation existing before then is expected to have change subsequently. Moreover, Figure 2 suggests that the volatility in the growth rates from the early 1920s through the 1930s was conspicuously higher than at other times. Therefore, we expect that deterministic components, including trends and intervention dummies, would play a role in the long-run equilibrium relation. 
Specifically, the events of 1930s may have had a permanent impact on equilibrium relations. A step dummy was used in modelling the long-run relation. We denote the step dummy variable by $D_{s} 30$ which takes on the value 0 until 1930 and 1 afterwards. Figure 1 also shows an impulse blip in 1920 which was expected to affect both the variables in the short-run. Thus, an impulse dummy, $D_{i} 20$, is created and takes on the value 1 for 1920 and 0 otherwise. We also need to check if there was statistically significant effect of World War II period on short-run dynamics and separate it out in case there was such an effect. A third dummy variable was created for this purpose, $D_{\text {WWII }}$, which is 1 for the period 1941-1945 and 0 otherwise.

Thus, the data generating process of the two variables is conjectured as an unrestricted VAR model specified as follows:

$$
\left(\begin{array}{c}
\ln A S_{t} \\
\ln G D P_{t}
\end{array}\right)=\sum_{k=1}^{p} \Pi_{k}\left(\begin{array}{c}
\ln A S_{t-k} \\
\ln G D P_{t-k}
\end{array}\right)+\Gamma\left(\begin{array}{c}
1 \\
T \\
D_{s} 30_{t} \\
D_{i} 20_{t} \\
D_{\text {WWIIt }}
\end{array}\right)+\boldsymbol{\varepsilon}_{t}
$$

where $p$ is the lag order to be determined by information criteria, $\Pi_{k}$ and $\Gamma$ are coefficient matrices with typical elements $\pi$.. and $\gamma$. ., and $\varepsilon_{t}$ has a normal distribution with zero mean and constant variance.

Table 3 presents computed information criteria on lag length selection and the least squares estimates of the unrestricted VAR together with diagnostic tests. Although both the AIC and HQC (Hannan-Quinn Criterion) point to a lag length of 5 , the model is specified as a VAR $(2)(p=2)$ model because not only is it indicated by the BIC but also the longer lag length did not result in improved diagnostic statistics over those reported in the table. The Portmanteau test indicates absence of residual autocorrelation of orders 1 through 6 . The outcomes of the Jarque-Bera normality test are less ideal, the skewness seems not very much different from 0 but the kurtosis is somewhat excessive (larger than 3). Although nonnormal residuals may be the case in the model, much of the asymptotic theory on which inference in dynamic models is based, can still work ([25], page 46). Since no further improvement can be achieved in terms of reducing the kurtosis, the model is deemed congruent with the data.

Equation (1) can be reformulated in the following VECM form which allows for analysis of short-run and long-run relations between Ad Spending and GDP upon imposing restrictions on functions of $\boldsymbol{\Pi}_{j}$ and $\boldsymbol{\Gamma}$.

$$
\left(\begin{array}{c}
\Delta \ln A S_{t} \\
\Delta \ln G D P_{t}
\end{array}\right)=-\Pi_{2}\left(\begin{array}{c}
\Delta \ln A S_{t-1} \\
\Delta \ln G D P_{t-1}
\end{array}\right)-\left(\mathbf{I}_{2}-\Pi_{1}-\Pi_{2}\right)\left(\begin{array}{c}
\ln A S_{t-1} \\
\ln G D P_{t-1}
\end{array}\right)+\Gamma\left(\begin{array}{c}
1 \\
T \\
D_{s} 30_{t} \\
D_{i} 20_{t} \\
D_{\text {WWIIt }}
\end{array}\right)+\boldsymbol{\varepsilon}_{t}
$$

Since both the variables show a deterministic trend, a linear combination of them may not result in cancellation of their deterministic trends. Therefore, the long-run equilibrium relation incorporating the shift in 1930 may be represented by $\boldsymbol{\beta}^{\prime} \boldsymbol{X}_{t}$ where $\boldsymbol{X}_{t}=\left(1, \ln G D P_{t}, \ln A S_{t}, T, D_{s} 30_{t}\right)^{\prime}$. The dimension of the cointegrating vector, $\boldsymbol{\beta}$, is of $1 \times 5$.

$$
\left(\begin{array}{l}
\ln x_{t} \\
\ln y_{t}
\end{array}\right)=\boldsymbol{\alpha} \boldsymbol{\beta}^{\prime}\left(\begin{array}{c}
1 \\
T \\
D_{s} 30_{t-1} \\
\ln A S_{t-1} \\
\ln G D P_{t-1}
\end{array}\right)-\Pi_{2}\left(\begin{array}{l}
\ln x_{t-1} \\
\ln y_{t-1}
\end{array}\right)+\Gamma^{*}\left(\begin{array}{c}
D i 20_{t} \\
D_{\text {WWIIt }}
\end{array}\right)+\boldsymbol{\varepsilon}_{t}
$$

where $\boldsymbol{\alpha} \boldsymbol{\beta}^{\prime}=\left(\tilde{\boldsymbol{\Gamma}}-\left(\mathbf{I}_{2}-\boldsymbol{\Pi}_{1}-\boldsymbol{\Pi}_{2}\right)\right)$ with $\tilde{\boldsymbol{\Gamma}}$ formed by the first three columns of $\boldsymbol{\Gamma}$ and $\boldsymbol{\Gamma}^{*}$ formed by the last two columns of $\boldsymbol{\Gamma}$.

Table 4 presents the cointegration results and VECM. The Johansen Trace Test on the value of $\gamma$ indicates $\ln A S$ and $\ln G D P$ are cointegrated controlling for a deterministic trend at $1 \%$ significance level, and there is a shift in their long-run equilibrium relation after 1930. 
Table 3. Estimation results of the unrestricted VAR.

\begin{tabular}{|c|c|c|c|c|c|c|c|}
\hline \multicolumn{8}{|c|}{ Diagnostics } \\
\hline \multicolumn{3}{|c|}{ Lag length } & \multirow{2}{*}{$\begin{array}{c}\text { Portmanteau } \\
\text { Tested order: } 6\end{array}$} & \multirow{2}{*}{ VAR equation } & \multicolumn{3}{|c|}{ Jarque-Bera } \\
\hline AIC & HQC & BIC & & & Test stat & Skewness & Kurtosis \\
\hline \multirow{2}{*}{5} & \multirow{2}{*}{5} & \multirow{2}{*}{2} & \multirow{2}{*}{18.84} & $\ln A S_{t}$ & 22.36 & 0.6832 & 4.7876 \\
\hline & & & & $\ln G D P_{t}$ & 16.41 & -0.3099 & 4.8251 \\
\hline \multicolumn{8}{|c|}{ VAR coefficients } \\
\hline & $\ln A S_{t-1}$ & $\ln G D P_{t-1}$ & $\ln A S_{t-2}$ & $\ln G D P_{t-2}$ & Ds30 & $D_{i} 20_{t}$ & $D_{\text {WWIIt }}$ \\
\hline $\ln A S_{t}$ & $0.404^{* * *}$ & $0.684^{* * *}$ & 0.167 & $-0.313^{* *}$ & $-0.186^{* * *}$ & $0.379^{* * *}$ & $-0.173^{* * *}$ \\
\hline \multirow[t]{2}{*}{$\ln G D P_{t}$} & -0.004 & $1.208^{* * * *}$ & -0.097 & $-0.325^{* * *}$ & $-0.227^{* * *}$ & 0.119 & 0.042 \\
\hline & & $\mathrm{T}$ & $\mathrm{C}$ & & & & \\
\hline $\ln A S_{t}$ & & 0.004 & $-0.944^{* *}$ & & & & \\
\hline $\ln G D P_{t}$ & & $0.016^{* * *}$ & $1.746^{* * *}$ & & & & \\
\hline
\end{tabular}

Table 4. Estimates of VECM.

\begin{tabular}{|c|c|c|c|c|c|c|}
\hline & \multicolumn{6}{|c|}{ Johansen Trace Test: $r=049.83^{* * *}, r=117.72^{* *}$} \\
\hline & \multicolumn{6}{|c|}{ VECM coefficients } \\
\hline & \multirow[t]{2}{*}{$\hat{\boldsymbol{\alpha}}$} & \multicolumn{5}{|c|}{$\hat{\boldsymbol{\beta}}$} \\
\hline & & $\ln A S_{t-1}$ & $\ln G D P_{t-1}$ & $D_{s} 30_{t-1}$ & $C$ & $T$ \\
\hline $\begin{array}{c}\Delta \ln A S_{t} \\
\Delta \ln G D P_{t}\end{array}$ & $\begin{array}{c}-0.327^{* * * *} \\
0.005\end{array}$ & 1 & $-1.263^{* * *}$ & 0.024 & $6.099^{* * *}$ & $0.019^{* * * *}$ \\
\hline \multirow{2}{*}{$\Delta \ln G D P_{t}$} & & \multicolumn{2}{|c|}{$\widehat{\mathbf{\Pi}}_{2}$} & \multicolumn{3}{|c|}{$\hat{\boldsymbol{\Gamma}}^{*}$} \\
\hline & & $\Delta \ln A S_{t-1}$ & $\Delta \ln G D P_{t-1}$ & $D_{\text {WWIIt }}$ & & $D_{i} 20_{t}$ \\
\hline$\Delta \ln A S_{t}$ & & $-0.121^{*}$ & $0.354^{* * *}$ & $-0.139^{* * *}$ & & $0.223^{* * *}$ \\
\hline$\Delta \ln G D P_{t}$ & & 0.105 & $0.516^{* * *}$ & 0.065 & & 0.059 \\
\hline
\end{tabular}

The long-run equilibrium equation can be written as

$$
\ln A S_{t}=-6.114+1.263 \ln G D P_{t}-0.024 D_{s} 30_{t}-0.020 T
$$

It suggests that the long-run elasticity of ad spending with respect to GDP is about 1.26 , with a trend of -2.0 per cent annual growth. The coefficient of $D_{s} 30$ indicates that the tempo of growth of ad spending increased after the break point. However, it should be noted that while the structural break as captured by $D_{s} 30$ is found significant in the unrestricted VAR, it becomes insignificant in determining their long-run relationship in the VECM model. Hence, it may be the case that the impacts of the structural change on the two variables have cancelled each other in the long-run.

The equilibrium error, which measures the deviation of ad spending from its long-run equilibrium path, is plotted in Figure 3.

It is conspicuous from Figure 3 that ad spending remained above its long-run equilibrium level from the beginning of the Great Depression all the way through to the beginning of the Second World War. For the remainder of the sample period afterwards, it is persistently below the equilibrium level.

The adjustment coefficient for $\Delta \ln A S_{t},-0.327$, is found significant, while that for $\Delta \ln G D P_{t}, 0.005$, is not. This suggests that in the short-run ad spending responds to equilibrium error in the previous year in such a way that if ad spending in the previous year is above the equilibrium level by 1 per cent, then ad spending in the current year will drop by 0.327 per cent. Also, the insignificance of the adjustment coefficient for GDP shows that the common trend that has been driving the equilibrium time path is generated by shocks to the GDP process. 


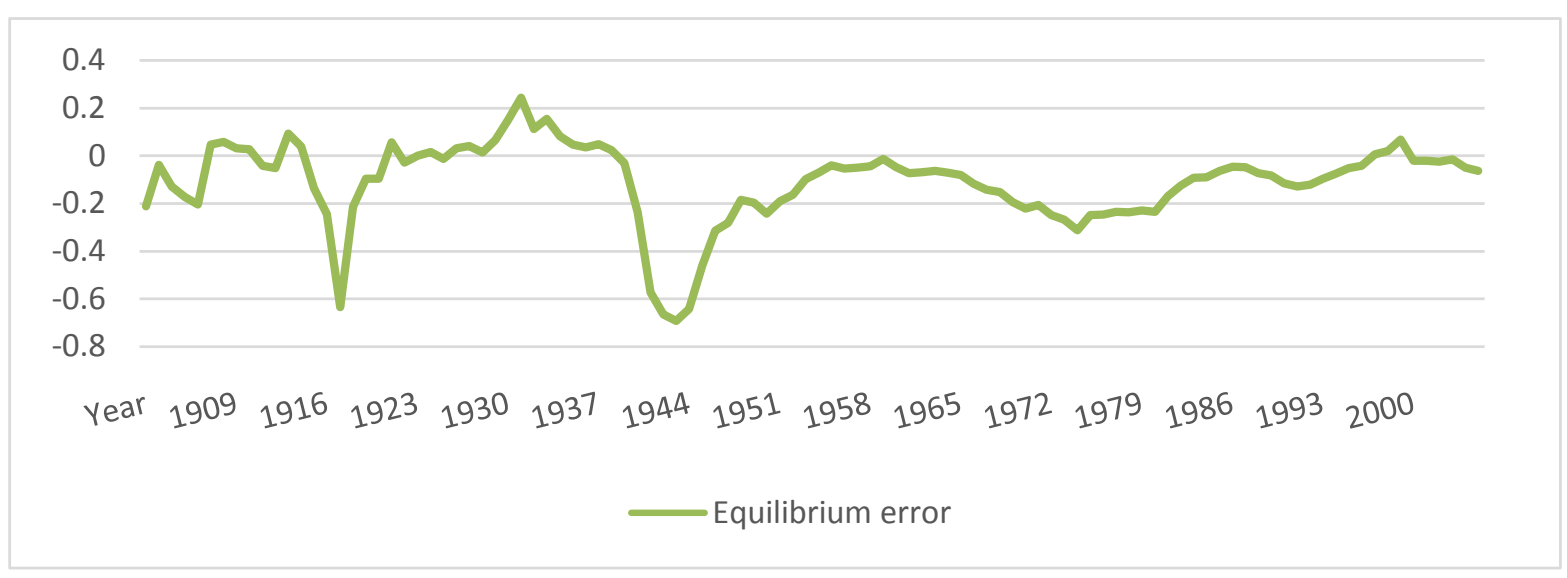

Figure 3. Equilibrium errors of advertisement spending.

\subsection{Granger Causality}

Finally we examined if current period GDP contains any information that can help predict the future values of ad spending or vice versa, i.e., the directions of Granger causality between the two. In the present setting, a bivariate vector autoregressive (VAR) model needs to be estimated to examine Granger causality. If any of the coefficients of the past values of GDP (ad spending) is significant in explaining the current ad spending (GDP), then GDP (ad spending) Granger causes ad spending (GDP). Non-stationarity of both variables generally requires additional work conducting significance tests. However in the light of Toda and Yamamoto [26], Granger causality between the two variables can be tested in the usual way in a VAR model where the lag length is equal to the optimal lag length plus one. That happens to be the case here as already discussed. From the reported VAR model it is clear that Granger-causality is one-way, namely, from GDP to advertisement spending. This finding is consistent with the results in the previous section that the two variables system was driven by shocks in the GDP process. The fact that current GDP growth contains information about subsequent increase of ad spending provides some leads about ad spending decisions as discussed in the next section.

\section{Discussion}

We will briefly comment on the econometric results to relate them with the issues discussed in earlier sections. In microeconomics a firm's ad spending is seen as an instrument of profit maximization. In industrial organization theory it is a strategic variable in industry level games. In either case ad spending and output are simultaneously determined in a maximization exercise. As they are determined together within the posited time period of the model, the question of causality is irrelevant in that context. The general result of cross-section studiesthat large campaigns and large firms occur together in samples - squares well with the view that large businesses spend more on ads which in turn keeps them large. This two-way dependence makes sense for established industries with stable market-share structure which generate the sample spaces for cross-sectional studies. However the question of causality acquires importance for understanding changing market share dynamics within industries and the entry of new firms. The issue is also vital for new products, sunrise industries and start-ups, which have important contribution to the growth of an economy. But they are not suitable samples for crosssectional empirical studies and hence we know very little about sales and advertisement relation in these areas. Hence in the aggregate the question of causality has a status that it does not have in industry level analysis.

Test results for Granger causality indicate the temporal precedence of GDP. It is beyond the scope of this paper to formulate and test secondary economic hypotheses supporting this result. But we forward a line of reasoning that can be built into a testable hypothesis. From cross-section studies it appears that in established businesses with relatively steady market share of member firms, ad spending and firm outputs are positively correlated and the regressions are robust. This would imply that in those industries ad spending attains a stable relation with industry output. To the extent that GDP increases from the production of these industries, increase of ad spending and GDP can be considered simultaneous in an observational sense. But the situation is different for the part of GDP coming from start-ups, emergent lines of business and new entrants to existing industries. As 
they enter the market or increase output, they introduce fresh advertisement initiatives. This could be a possible explanation of GDP Granger causing aggregate ad spending. Further, we expect this effect to be multiplied because the campaign of newcomers triggers off retaliatory spending by incumbent firms and industries.

Taking cointegration and Granger causality results together, it appears that as GDP increases it causes ad spending to increase at a rate faster than its own growth. The elasticity is estimated at 1.26. Faster growth of ad spending compared with GDP appears to be related to the continuously changing composition of GDP over the last century. There have been large-scale shifts towards services and manufactures away from primary goods, as also an increase in the ratio of private consumption expenditure to GDP. Shift of consumption spending towards fast moving consumer goods and personal services has also contributed to the trend. Additionally, within private consumption there is an increase of the proportion of experience and credence goods. All these shifts are expected to raise the ad-intensity of sales and hence GDP.

More recently, the centralization of retailing in large supermarkets where multi-product and multi-brand retailing is conducted by a single seller has facilitated effective advertising in retail business. There is economy of scale and scope in advertising by a single retailer of the full range of goods of a supermarket. This boosts the use of advertisement as a potent sales tool in retailing. Supermarket-type retailing has now been adopted by vendors beyond food, grocery and ordinary consumption goods. There are supermarket-style stores for example for furniture and household products; household electrical and white goods; do-it-yourself tools and equipment; garden material and plants; books and stationary; and electronic goods. Advertisement is one of the most potent tools for competition among local oligopolies of these retailers too. More recently, online sale has led to the substitution of several traditional sales expenses by advertisement, as the logistics of online sale does away with these traditional sales supports. This also has contributed to the tendency ${ }^{10}$.

As reported above, faster growth relative to GDP is accompanied with a negative autonomous trend of ad spending. This trend appears consistent with the continuous technical progress in advertisement. First of all, the number of platforms has increased steadily in the last century so that now there is a choice of the press, postal mail, billboards, radio, TV, mobile phones, emails, the internet and the social electronic media for advertisement and dissemination. Platforms vary in suitability and targets when advertising different products, and hence a vendor can now build an optimal mix of spending on a number of platforms as a function of its product mix $x^{11}$. This is expected to reduce advertisement cost per unit sale. Further, technical progress has cut down the unit cost of realizing a dollar of purchase response in all platforms ${ }^{12}$. Advertising firms constantly work on campaign techniques to reduce the noise element from responses so that conversion of response to sale can increase. For example, conversion rates for radio and TV advertisement occurred in the nineties through soliciting time-bound response from audience and viewers via dedicated telephone numbers. Likewise, continuous improvement occurs in web-based advertisement where agencies work on separating casual click-through from those generating genuine enquiry and eventual purchase ${ }^{13}$. Advertisers also conduct significant research in personal and consumer psychology. They have developed campaign strategies suiting products and markets with differing characteristics across platforms. We also note that these developments have made clients more aware of effectiveness metrics, resulting in ad agencies themselves focusing more on improving them. All these developments are expected to have a downward effect on ad cost per unit sale which show up as a negative autonomous trend.

\section{Conclusion}

The present research was motivated by the lack of studies on the dynamic long-run relationship between income and ad spending. Studies using firm level data can produce ambivalent longer-run consequences for the firm itself and the industry to which it belongs. As shown in the paper, faster growth relative to GDP was accompanied with a negative autonomous trend of ad spending. This trend appeared consistent with the continuous technical progress in advertisement; the availability of the internet and the related social electronic media had seen the rise

\footnotetext{
${ }^{10}$ Surveys show that retailers have emerged as the largest on-line advertisers. See for example an eMarketer estimate [27].

${ }^{11}$ For a systematic discussion of issues see [28].

${ }^{12}$ Measurement of unit cost is related to the measurement of effectiveness. Research on measuring and improving effectiveness is a busy area across disciplines like consumer psychology to marketing. An early overview of ideas was provided in [29]. For a more recent discussion, see the papers in [30]. In recent decades there is continuing research on quantifying the effectiveness of web-based advertisement by academics and advertisement firms (see footnote 13). There is also an effectiveness literature on specific businesses like travel and hospitality. ${ }^{13}$ For example the US patent by Meggido and Zhu [31] improves the effectiveness of web advertising. There is a large and growing class of such methods. See [32]-[34] and the references in them. Similar exercises for other ad platforms also continue, e.g., [35] provides an interesting study of traditional outdoor advertising.
} 
of the cost-effectiveness of advertisement and dissemination. While existence of cointegration between the two variables was not unexpected, that this long-run equilibrium relationship statistically unaffected by the Great Depression in the 1930s was intriguing. The explanation we offer is that the impacts of the structural change on the two variables have cancelled each other in the long-run. The one-way Granger causality results showed that as GDP increases it caused ad spending to increase at a rate faster than its own growth. A further research topic may be an investigation of the role of internet-based advertisement in cross-border freight movement.

\section{References}

[1] Chamberlin, E. (1933) The Theory of Monopolistic Competition. Harvard University Press, Cambridge, MA.

[2] Sherman, S.A. (1900) Advertising in the United States. Publications of the American Statistical Association, 7, 1-44. http://dx.doi.org/10.2307/2276425

[3] Presbrey, F. (1929) The History and Development of Advertising. Greenwood Press, New York.

[4] Garvey, E.G. (1996) The Adman in the Parlor: Magazines and the Gendering of Consumer Culture, 1880s to 1910s. Oxford University Press, New York. http://dx.doi.org/10.1093/acprof:oso/9780195108224.001.0001

[5] Schmalensee, R. (1972) The Economics of Advertising. North Holland, Amsterdam.

[6] Albert, A. and Reid, B. (2011) The Contribution of the Advertising Industry to the UK Economy. Credos. http://www.credos.org.uk/write/Images/ThecontributionofadvertisingtotheUKeconomy311011.pdf

[7] Raimondi, M.J. and Klein, L. (2004) Comprehensive Economic Impact of Advertising Expenditures, Association of National Advertisers, Global Insights Group. http://bit.ly/gUrHde

[8] Bain, J.S. (1956) Barriers to New Competition: Their Character and Consequences in Manufacturing Industries. Harvard University Press, Cambridge, MA. http://dx.doi.org/10.4159/harvard.9780674188037

[9] Comanor, W.S. and Wilson, T.A. (1967) Advertising, Market Structure and Performance. The Review of Economics and Statistics, 49, 423-440. http://dx.doi.org/10.2307/1928327

[10] Schmalensee, R. (1989) Inter-Industry Studies of Structure and Performance. In: Schmalensee, R. and Willig, R., Eds. Handbook of Industrial Organization, North-Holland, Amsterdam, Vol. 1, 475-535.

[11] Bagwell, K. (2007) The Economic Analysis of Advertising. In: Armstrong, M. and Porter, R., Eds., Handbook of Industrial Organization, Vol. 3, North-Holland, Amsterdam, 1701-1844.

[12] Braithwaite, D. (1928) The Economic Effects of Advertisement. Economic Journal, 38, 16-37. http://dx.doi.org/10.2307/2224394

[13] Nelson, P. (1974) Advertising as Information. Journal of Political Economy, 82, 729-754. http://dx.doi.org/10.1086/260231

[14] Nelson, P. (1970) Information and Consumer Behavior. Journal of Political Economy, 78, 311-329. http://dx.doi.org/10.1086/259630

[15] Nelson, P. (1974) The Economic Value of Advertising. In: Brozen, Y., Ed., Advertising and Society, New York University Press, New York, 43-66.

[16] Nelson, C.R. and Plosser, C.R. (1982) Trends and Random Walks in Macroeconmic Time Series: Some Evidence and Implications. Journal of Monetary Economics, 10, 139-162. http://dx.doi.org/10.1016/0304-3932(82)90012-5

[17] Dickey, D.A. and Fuller, W.A. (1979) Distribution of the Estimators for Autoregressive Time Series with a Unit Root. Journal of the American Statistical Association, 74, 427-431.

[18] Perron, P. (1989) The Great Crash, the Oil Price Shock, and the Unit Root Hypothesis. Econometrica, 57, $1361-1401$. http://dx.doi.org/10.2307/1913712

[19] Zivot, E. and Andrews, D.W.K. (1992) Further Evidence on the Great Crash, the Oil-Price Shock, and the Unit-Root Hypothesis. Journal of Business and Economic Statistics, 10, 251-270.

[20] Phillips, P.C.B. and Perron, P. (1988) Testing for a Unit Root in Time Series Regression. Biometrika, 75, 335-346. http://dx.doi.org/10.1093/biomet/75.2.335

[21] Elliott, G., Rothenberg, T.J. and Stock, J.H. (1996) Efficient Tests for an Autoregressive Unit Root. Econometrica, 64, 813-836.

[22] Kwiatkowski, D., Phillips, P.C.B., Schmidt, P. and Shin, Y. (1992) Testing the Null Hypothesis of Stationarity against the Alternative of a Unit Root. Journal of Econometrics, 54, 159-178. http://dx.doi.org/10.1016/0304-4076(92)90104-Y

[23] Johansen, S. (1988) Statistical Analysis of Cointegration Vectors. Journal of Economic Dynamics and Control, 12, 231-254. http://dx.doi.org/10.1016/0165-1889(88)90041-3 
[24] Hendry, D.F. and Juselius, K. (2000) Explaining Co-Integration Analysis. Part 2. Energy Journal, 22, 1-52.

[25] Lütkepohl, H. and Krätzig, M. (2004) Applied Time Series Econometrics. Cambridge University Press, Cambridge.

[26] Toda, H.Y. and Yamamoto, T. (1995) Statistical Inference in Vector Autoregressions with Possibly Integrated Processes. Journal of Econometrics, 66, 225-250. http://dx.doi.org/10.1016/0304-4076(94)01616-8

[27] http://www.retailcustomerexperience.com/articles/retail-industry-continues-to-lead-in-online-ad-spending/

[28] Zanville, S.J. and Baron, R.B. (2010) Advertising Media Planning. McGraw-Hill, New York.

[29] Lucas, D.B. and Henderson, B.S. (1963) Measuring Advertising Effectiveness. McGraw-Hill Series in Marketing and Advertising, McGraw-Hill Book Company, New York.

[30] Wells, W.D. (Ed.) (1997) Measuring Advertisement Effectiveness. Psychology Press, New York.

[31] Meggido, N. and Zhu, X. (2005) US Patent No. US6892181B1.

[32] Dreze, X. and Zufryden, F. (1997) Testing Website Design and Promotional Content. Journal of Advertising Research, 37, 77-91.

[33] Eighmey, J. (1998) Profiling User Responses to Commercial Websites. Journal of Advertising Research, 38, 7-18.

[34] Spiliopoulou, M., Pohle, C. and Faulstich, L. (1999) Improving the Effectiveness of a Web Site with Web Usage Mining. WebKDD Workshop 99, San Diego, 15 August 1999.

[35] Bhargava, M., Donthu, N. and Rosanne, C. (1994) Improving the Effectiveness of Outdoor Advertising: Lessons from a Study of 282 Campaigns. Journal of Advertising Research, 34, 46-55. 